\title{
Single-letter coloring and spatial cuing do not eliminate or reduce a semantic contribution to the Stroop effect
}

\author{
Maria Augustinova, Valentin Flaudias, And Ludovic Ferrand \\ CNRS and University Blaise Pascal, Clermont-Ferrand, France
}

\begin{abstract}
The automaticity of semantic activation in the Stroop task is still the subject of considerable debate (Augustinova \& Ferrand, 2007; Manwell, Roberts, \& Besner, 2004). The present experiments were designed to assess whether coloring and cuing a single letter (vs. all letters) in the Stroop task reliably eliminates semantically based Stroop interference or whether the elimination observed by Manwell et al. was due to insufficient statistical power. Experiment 1 was an exact replication of the experiment conducted by Manwell and colleagues and involved a large population. Experiment 2 replicated and extended Experiment 1 by controlling for initial fixation. In line with previous findings obtained by Augustinova and Ferrand, both experiments indicated that coloring and cuing a single letter failed to eliminate or even reduce the semantically based Stroop effect. Thus, these results add to the growing body of evidence suggesting that semantic activation in the Stroop task is automatic.
\end{abstract}

The Stroop task (Stroop, 1935) is a widely used paradigm in the field of visual word recognition because it generates data that are considered to be fundamental to the claim that semantic activation (SA) is automatic in the sense that it occurs without intent and cannot be prevented (see, e.g., Neely \& Kahan, 2001; Posner \& Snyder, 1975; but see also, e.g., Bargh, 1994, and Reynolds \& Besner, 2006 , for a different and/or broader conceptualization of automaticity).

In the Stroop task (see MacLeod, 1991, 2005, for reviews), participants are asked to identify the font color of target words as quickly and accurately as possible. In standard incongruent trials, a target denotes a color word that is different from the font color (e.g., the word blue displayed in green font). The standard Stroop effect corresponds to the difference in mean response latencies between this type of standard incongruent trial and neutral trials in which the target is a word that is neutral with respect to color (e.g., table displayed in green font). Within the SA automaticity perspective, this type of interference is considered as evidence that readers cannot refrain from computing the lexical and semantic representations of the word that is read, even when such computations impair performance (see, e.g., Brown, Gore, \& Carr, 2002).

Neely and Kahan (2001) have challenged the fundamental postulates of this interpretation by emphasizing that standard Stroop interference reflects not only semantically based response competition, but also nonsemantic or task-relevant response competition (see also Dalrymple-Alford, 1972; Klein, 1964). To eliminate the impact of the latter type of competition, Neely and Kahan suggested that standard incongruent trials (e.g., the word blue displayed in green font) should be replaced by trials on which target words are simply associated with a color (e.g., sky displayed in green font). Any significant positive difference in mean response latencies between colorassociated trials and neutral trials (i.e., a semantically based Stroop effect) could then be interpreted as prima facie evidence that SA is automatic, whereas the failure to observe this effect would support the opposite conclusion (Besner, Stolz, \& Boutilier, 1997; Manwell, Roberts, \& Besner, 2004; Stolz \& Besner, 1999). However, it is still far from certain that the semantically based Stroop effect can be reliably eliminated.

For instance, Manwell et al. (2004) introduced variations into their incongruent trials. On half of these trials, only a single letter of the target word was spatially cued by an arrow and was displayed in a font color different from that named by the target word (e.g., only the letter $b$ in the word blue appeared in green font). The rest of the target word was displayed in another color font that was incongruent with regard to the response set (e.g., if $b$ in the word blue appeared in green font, the remaining letters were displayed in red font). Under these conditions, the semantically based Stroop effect was found to be nonsignificant (i.e., $7 \mathrm{msec}$, as compared with the significant and reliably larger amplitude of $28 \mathrm{msec}$ when all the letters to be named were cued/colored; see Table 1). As a result, Manwell and colleagues suggested that coloring and cuing a single letter (as opposed to all the letters) in a word reduces the amplitude of the semantically based Stroop effect to a nonsignificant level (i.e., eliminates it). 
Table 1

Summary of Studies Investigating the Effect of Coloring and Cuing a Single Letter (vs. All Letters) in the Stroop Task on the Elimination of the Semantically Based Stroop Interference

\begin{tabular}{|c|c|c|c|c|c|c|}
\hline Study & Experiment & NP & CLL & $\begin{array}{c}\text { Coloring of } \\
\text { Remaining Letters }\end{array}$ & $\begin{array}{l}\text { Semantic Stroop } \\
\text { Effect, All Letters } \\
\text { Colored/Cued }\end{array}$ & $\begin{array}{c}\text { Semantic Stroop } \\
\text { Effect, Single Letter } \\
\text { Colored/Cued }\end{array}$ \\
\hline $\begin{array}{l}\text { Manwell, Roberts, \& } \\
\text { Besner }(2004)^{\mathrm{a}}\end{array}$ & 1 & 16 & Initial, Middle, End ${ }^{b}$ & $\begin{array}{l}\text { A single color from the } \\
\text { response set }\end{array}$ & $28^{* *}$ & 7 n.s. \\
\hline Manwell et al. (2004)a & $\mathrm{na}^{\mathrm{c}}$ & 16 & Initial, Middle, End ${ }^{b}$ & $\begin{array}{l}\text { Gray, which was not in } \\
\text { the response set }\end{array}$ & $\mathrm{na}^{\mathrm{c}}$ & $18^{* *}$ \\
\hline $\begin{array}{l}\text { Augustinova \& Ferrand } \\
(2007)^{\mathrm{a}}\end{array}$ & 1 & 21 & Initial onlyd & $\begin{array}{l}\text { A single color from the } \\
\text { response set }\end{array}$ & $24^{* *}$ & $18^{*}$ \\
\hline $\begin{array}{l}\text { Augustinova \& Ferrand } \\
\qquad(2007)^{\mathrm{a}}\end{array}$ & 2 & 24 & Initial only ${ }^{\mathrm{d}}$ & $\begin{array}{l}\text { Gray, which was not in } \\
\text { the response set }\end{array}$ & $52^{*}$ & $52^{*}$ \\
\hline
\end{tabular}

Note-NP, number of participants; CLL, cued letter location; n.s., not significant; na, not available. $\quad{ }^{*} p<.05 . \quad{ }^{* *} p<.005 . \quad{ }^{a} \mathrm{~A} 400-\mathrm{msec}(\mathrm{Man}-$ well et al., 2004) or 500-msec (Augustinova \& Ferrand, 2007) fixation point appeared at the center of the video monitor; when the fixation point disappeared, arrows appeared above and below the locations where the letter(s) carrying the to-be-named ink color would appear 125 msec later; the word appeared and the arrows remained present until a response was made; the fixation point for the next trial then appeared 500 msec later. bThe middle letter always appeared at the fixation location. cThis experiment was reported in the Discussion section of Manwell et al. (2004), and no other details were given. dThe first letter of the word always appeared at the fixation point.

It should be noted that this conclusion was derived from a single experiment involving 16 participants. Thus, the 28 -msec effect associated with a Student's $t$ of 3.52 corresponds to a correlated Cohen's $d$ of 1.24 . The power required to detect an effect of this size, with $p=.05$ in a one-tailed test, is .94 . However, if coloring and cuing a single letter halves the 28-msec effect, the power to detect the 14-msec $(d=0.62)$ effect with the same sample size is only .53. Consequently, these analyses ${ }^{1}$ suggest that Manwell et al.'s (2004) failure to detect the semantically based Stroop effect in a single-letter cued/colored condition could have been a Type II error.

It should be noted that the above reasoning is consistent with the results from another (unpublished) data set based on a slightly different implementation of single-letter coloring (see Table 1 for more details) that was presented in Manwell et al.'s (2004) discussion. In this experiment, and contrary to the main data set reported by the authors and described above, coloring and cuing a single letter (vs. all letters) in a word significantly reduced but did not eliminate the amplitude of the semantically based Stroop effect.

Furthermore, Augustinova and Ferrand (2007) have reported two experiments using French words that differed from the procedure adopted by Manwell et al. (2004) only in the fact that in the single-letter condition, the color carrier was always the first letter of the word. This was done in order to reduce possible fluctuations in initial fixation due to the fact that the initial fixation cue and cued/colored letter did not always appear in the same location in Manwell et al.'s experiments. ${ }^{2}$ By controlling for initial fixation as described above, these authors found a significant semantically based Stroop effect in both experiments. The magnitude of this effect was $18 \mathrm{msec}$ in the single-letter cued/colored condition in Experiment 1 (as compared with $24 \mathrm{msec}$ when all the letters were cued/colored) and $52 \mathrm{msec}$ in Experiment 2 (as compared with $52 \mathrm{msec}$ when all the letters were cued/colored; see Table 1). Thus the results obtained by Augustinova and Ferrand, unlike those of Manwell and colleagues, suggest that coloring and cuing a single letter (vs. all letters) in a word neither eliminate nor reduce the amplitude of the semantically based Stroop effect.

Given the discrepancies between the different sets of data discussed above, two experiments were conducted in order to determine whether coloring and cuing a single letter (vs. all letters) in a word reliably eliminate semantically based Stroop interference. To this end, we first conducted an exact replication of Manwell et al.'s (2004) study (Experiment 1) using a large sample size $(N=79)$. In addition to the fact that there were some differences between the methodologies used by Manwell et al. and Augustinova and Ferrand (2007; see Table 1 for a summary of these differences), this replication was performed in order to address the possibility that the null semantically based Stroop effect observed by Manwell et al. may well have been due to a lack of statistical power. Experiment 2 was designed to generalize and extend the findings of Experiment 1 while simultaneously retaining some important characteristics of Manwell et al.'s experimental manipulations (i.e., the variation in the letter position and spatial cuing) and controlling for the position of initial fixation (Augustinova \& Ferrand, 2007). Consequently, the procedure adopted in Experiment 2 was the same as that used by Parris, Sharma, and Weekes (2007, Experiment 2). This controls for initial fixation by shifting the target word horizontally from one trial to the next in such a way that the colored letter to be named always appears at the same location as the preceding central fixation cue, thus simultaneously permitting variations in letter position and spatial cuing (see Figure 1). ${ }^{3}$

\section{EXPERIMENTS 1 AND 2}

\section{Method}

Participants. One hundred forty-six psychology undergraduates at Blaise Pascal University, Clermont-Ferrand, France took part in these experiments (79 in Experiment 1 and 67 in Experiment 2) in exchange for a course credit. They were all native French speakers, had normal or corrected-to-normal vision, and were not color-blind.

Stimuli. Exactly the same stimuli were used in both Experiments 1 and 2. These consisted of six neutral words (balcon [balcony], robe 
Incongruent Condition

Initial Position

Middle Position

End Position green green $\mathbf{V S}$ •

Optimal Viewing Position

green

Fixation Cue

$+$

\section{Color-Associated Condition}

Initial Position

Middle Position

End Position

lemon lemon lemon

\section{VS .}

\section{Optimal Viewing Position}

\section{lemon}

Figure 1. Example of stimulus presentation used in Experiment 2 . The boldface letter represents a letter colored differently from the other letters (in red font, in this example). The other letters (not set in boldface) are also colored, but in a different color font (in blue font, in this example). From "An Optimal Viewing Position Effect in the Stroop Task When Only One Letter Is the Color Carrier," by B. A. Parris, D. Sharma, and B. Weekes, 2007, Experimental Psychology, 54, p. 276. Copyright 2007 by Hogrefe \& Huber Publishers (www.hogrefe.com). Adapted with permission.

[dress], pont [bridge], chien [dog], train [train], and studio [studio]), six color-associated words (tomate [tomato], maïs [corn], ciel [sky], salade [salad], chocolat [chocolate], and carotte [carrot]), and six color words (rouge [red], jaune [yellow], bleu [blue], vert [green], marron [brown], and orange [orange]). In each condition, all the stimuli were similar in length $(5,5.8$, and 5 letters on average for the color-associated, the standard incongruent, and the neutral conditions, respectively) and frequency $(53,60$, and 65 occurrences per million for the color-associated, the standard incongruent, and the neutral conditions, respectively) according to Lexique (New, Pallier, Brysbaert, \& Ferrand, 2004). The color-associated and color words were always presented in incongruent colors (i.e., carotte [carrot] appeared only in red, yellow, green, brown, or blue).

Design. Experiment 1 consisted of a 3 (type of stimulus: standard incongruent vs. color-associated incongruent vs. neutral) $\times 2$ (level of coloring/cuing: single letter vs. all letters) within-subjects design. Experiment 2 consisted of a 3 (type of stimulus: standard incongruent vs. color-associated incongruent vs. neutral) $\times 2$ (level of coloring/cuing: single letter vs. all letters) $\times 2$ (stimulus location: random vs. optimal viewing position [OVP]) mixed design, with stimulus location as a between-subjects factor and type of stimulus and level of coloring/cuing as within-subjects factors. In the random stimulus location condition, the colored center of the screen corresponded to the initial, middle, or final letter.

Procedure. The participants were seated approximately $50 \mathrm{~cm}$ from a 17 -in. Dell color monitor. Stimulus presentation and data were controlled by DMDX (Forster \& Forster, 2003) run on a PC. The participants' responses were recorded via a Koss 70-dB microphone headset and stored on the hard disk. Response latencies were measured to the nearest millisecond.

The stimuli were presented individually in lowercase letters. On average, each word subtended a visual angle $0.9^{\circ}$ in height $\times 3.0^{\circ}$ in width. Either all the letters were displayed in the same color or one of the letters was colored differently from the rest, with the result that all the remaining letters appeared in a color that was incongruent with regard to the response set. For instance, if a single letter in ciel [sky] appeared in red, the rest of the letters were colored green.

It should be remembered that, in the same way as in Manwell et al. (2004), the participants were instructed to name the color of the letter(s) indicated by arrows (i.e., cued) as quickly and accurately as possible and to ignore everything else in the display. To this end, exactly the same cuing procedure as in Manwell et al. was used in Experiment 1. At the beginning of each trial, a fixation cross ("+") appeared in the center of the screen, and all the stimuli were presented with the middle letter positioned at the fixation point. The participants were instructed to concentrate on the fixation cross, which was presented in the center of the screen for $500 \mathrm{msec}$ and then replaced by a spatial cue consisting of small arrows (visual angle $1.2^{\circ}$ in height) displayed $0.6^{\circ}$ above and below the position subsequently occupied by the target letter. In the all-letters cued/colored condition, an arrow appeared above and below each letter position. In the single-letter cued/colored condition, an arrow appeared above and below the target letter position. The arrows remained on the screen for $125 \mathrm{msec}$, after which the stimulus appeared. The entire display remained on the screen until a response was made. The next trial appeared $500 \mathrm{msec}$ after the response.

The procedure used in Experiment 2 was identical to that of Experiment 1 , except that the stimuli shifted horizontally from trial to trial in such a way that the colored letter to be named always appeared in the same location as the preceding central fixation cue (see Figure 1). Consequently, the location of the initial fixation was controlled for (Parris et al., 2007).

The two experiments began with a set of 12 practice trials that were followed by the 180 experimental trials. There were 30 trials for each level of letter coloring/cuing and stimulus type, thus resulting in a total of 180 experimental trials. All the conditions varied randomly within a single block of trials throughout the experiment.

\section{Results}

Experiment 1: Replication of Manwell et al. (2004). Correct mean naming latencies (see Table 2) were first analyzed in a 3 (type of stimulus: standard incongruent vs. color-associated incongruent vs. neutral) $\times 2$ (level of coloring/cuing: single letter vs. all letters) repeated measures ANOVA. Latencies longer than $3 S D$ s above or below each participant's mean response latency observed in each condition (accounting for less than $4.9 \%$ of the total data) were excluded from this analysis.

Since there was a significant Stroop effect in all conditions (see $t$ values presented in Table 2), the amplitudes of these effects, together with differences in percentages of errors (see Table 2), were subsequently analyzed in a 2 (type of Stroop effect: standard vs. semantically based) $\times 2$ (level of coloring/cuing: single letter vs. all letters) repeated measures ANOVA.

The analysis of the amplitudes (see Table 2) revealed significant main effects of the type of Stroop effect $\left[F(1,78)=58.60, p<.001, \eta_{\mathrm{p}}^{2}=.43\right]$ and of letter coloring/cuing $\left[F(1,78)=12.73, p<.001, \eta_{\mathrm{p}}^{2}=.14\right]$, with these factors also exhibiting a significant interaction $\left[F(1,78)=46.97, p<.001, \eta_{\mathrm{p}}^{2}=.38\right]$. The planned comparisons showed that coloring and cuing a single letter (vs. all letters) in a word significantly reduced the amplitude of the standard Stroop effect $\left[t(78)=6.60, p<.001, \eta_{\mathrm{p}}^{2}=\right.$ .36] but had no effect on the amplitude of the semantically based Stroop effect $[t(78)=-0.79, p=.43$, n.s. $]$. 
Table 2

Mean Correct Naming Latencies (RTs, in Milliseconds; With Standard Deviations) and Percentages of Errors As a Function of Type of Stimulus and Level of Coloring/ Cuing in Experiment 1 (Replication of Manwell, Roberts, \& Besner, 2004)

\begin{tabular}{|c|c|c|c|c|c|c|}
\hline \multirow[b]{3}{*}{ Type of Stimulus } & \multicolumn{3}{|c|}{ All Letters Cued/Colored } & \multicolumn{3}{|c|}{ One Letter Cued/Colored } \\
\hline & \multicolumn{2}{|c|}{ RT } & \multirow[b]{2}{*}{$\%$ ER } & \multicolumn{2}{|c|}{ RT } & \multirow[b]{2}{*}{$\%$ ER } \\
\hline & $M$ & $S D$ & & M & $S D$ & \\
\hline Incongruent & 800 & 115 & 2.28 & 781 & 92 & 1.77 \\
\hline Color-associated & 749 & 93 & 0.67 & 773 & 96 & 1.22 \\
\hline Neutral & 731 & 94 & 0.72 & 751 & 94 & 0.70 \\
\hline \multicolumn{7}{|l|}{ Difference } \\
\hline Standard Stroop effect & \multicolumn{2}{|c|}{$\begin{array}{c}+69 \\
t(78)=12.06 \\
p<.001\end{array}$} & 1.56 & \multicolumn{2}{|c|}{$\begin{array}{c}+30 \\
t(78)=6.59 \\
p<.001\end{array}$} & 1.07 \\
\hline Semantic Stroop effect & \multicolumn{2}{|c|}{$\begin{array}{c}+18 \\
t(78)=4.26\end{array}$} & -0.04 & \multicolumn{2}{|c|}{$\begin{array}{c}+22 \\
t(78)=6.34\end{array}$} & 0.52 \\
\hline
\end{tabular}

The analysis of differences in percentages of errors (see Table 2) revealed a significant main effect of the type of Stroop effect $\left[F(1,78)=22.91, p<.001, \eta_{\mathrm{p}}^{2}=.22\right]$, as indicated by a significant interaction between the type of Stroop effect and level of letter coloring/cuing $[F(1,78)=$ $\left.5.27, p<.05, \eta_{\mathrm{p}}^{2}=.06\right]$. Subsequent planned comparisons revealed that coloring and cuing a single letter (vs. all letters) in a word had no effect on differences in percentages of errors in either the standard or the semantically related Stroop effect $[t(78)=1.08, p=.28$, n.s.; $t(78)=$ $-1.53, p=.13$, n.s.].

Experiment 2: Control for initial fixation. Correct mean naming latencies (see Table 3 ) were first analyzed in a 3 (type of stimulus: standard incongruent vs. colorassociated incongruent vs. neutral) $\times 2$ (level of coloring/ cuing: single letter vs. all letters) $\times 2$ (stimulus location: random vs. OVP) repeated measures ANOVA, with the latter factor used as a between-subjects variable. Latencies longer than $3 S D$ s above or below each participant's mean response latency observed in each condition (accounting for less than $3.74 \%$ of the total data) were excluded from this analysis.
Since there was a significant Stroop effect in all conditions (see $t$ values reported in Table 3), the amplitudes of these effects and differences in percentages of errors were analyzed in a 2 (type of Stroop effect: standard vs. semantically based) $\times 2$ (level of coloring/cuing: single letter vs. all letters) $\times 2$ (stimulus location: random vs. OVP) repeated measures ANOVA, with the latter factor as a between-subjects variable.

The analysis of amplitudes (see Table 3 ) revealed significant main effects of the type of Stroop effect $[F(1,65)=$ $\left.100.52, p<.001, \eta_{\mathrm{p}}^{2}=.61\right]$ and of letter coloring/cuing $\left[F(1,65)=21.06, p<.001, \eta_{\mathrm{p}}^{2}=.24\right]$. These two factors also interacted significantly $[F(1,65)=41.25, p<$ $\left..001, \eta_{\mathrm{p}}^{2}=.39\right]$, thus indicating that coloring and cuing a single letter (vs. all letters) in a word significantly reduced the amplitude of the standard Stroop effect $[t(66)=6.12$, $\left.p<.001, \eta_{\mathrm{p}}^{2}=.36\right]$ but had no effect on the amplitude of the semantically based Stroop effect, which remained unchanged $[t(66)=-0.26, p=.79$, n.s.]. It should be noted that the latter interaction was not influenced by the location of the stimulus, as the nonsignificant three-way interaction indicates $[F(1,65)=2.64, p=.11$, n.s. $]$. Con-

Table 3

Mean Correct Naming Latencies (RTs, in Milliseconds; With Standard Deviations) and Percentages of Errors As a Function of Type of Stimulus, Level of Coloring/Cuing, and Stimulus Location in Experiment 2 (Control for Initial Fixation)

\begin{tabular}{|c|c|c|c|c|c|c|c|c|c|c|c|c|}
\hline \multirow[b]{5}{*}{ Type of Stimulus } & \multicolumn{12}{|c|}{ Location of Colored Letter } \\
\hline & \multicolumn{6}{|c|}{ Random (Initial, Middle, End) } & \multicolumn{6}{|c|}{ Optimal Viewing Position } \\
\hline & \multicolumn{3}{|c|}{$\begin{array}{c}\text { All Letters Cued/ } \\
\text { Colored }\end{array}$} & \multicolumn{3}{|c|}{$\begin{array}{c}\text { One Letter Cued/ } \\
\text { Colored }\end{array}$} & \multicolumn{3}{|c|}{$\begin{array}{l}\text { All Letters Cued/ } \\
\text { Colored }\end{array}$} & \multicolumn{3}{|c|}{$\begin{array}{c}\text { One Letter Cued/ } \\
\text { Colored }\end{array}$} \\
\hline & \multicolumn{2}{|c|}{ RT } & \multirow[b]{2}{*}{$\%$ ER } & \multicolumn{2}{|c|}{ RT } & \multirow[b]{2}{*}{$\%$ ER } & \multicolumn{2}{|c|}{ RT } & \multirow[b]{2}{*}{$\%$ ER } & \multicolumn{2}{|c|}{ RT } & \multirow[b]{2}{*}{$\% \mathrm{ER}$} \\
\hline & $M$ & $S D$ & & $M$ & $S D$ & & $M$ & $S D$ & & $M$ & $S D$ & \\
\hline Incongruent & 806 & 125 & 4.10 & 787 & 101 & 1.81 & 822 & 121 & 3.90 & 770 & 87 & 2.08 \\
\hline Color-associated & 738 & 97 & 0.76 & 760 & 91 & 1.52 & 740 & 88 & 1.46 & 755 & 81 & 1.25 \\
\hline Neutral & 726 & 93 & 0.57 & 741 & 99 & 1.28 & 720 & 88 & 0.73 & 739 & 85 & 1.19 \\
\hline \multicolumn{13}{|l|}{ Difference } \\
\hline Standard Stroop effect & \multirow{2}{*}{\multicolumn{2}{|c|}{$\begin{array}{c}+80 \\
t(34)=9.26 \\
p<.001 \\
+12 \\
t(34)=2.09 \\
p<.05\end{array}$}} & 3.52 & \multirow{2}{*}{\multicolumn{2}{|c|}{$\begin{array}{c}+46 \\
t(34)=5.94 \\
p<.001 \\
+19 \\
t(34)=2.79 \\
p<.01\end{array}$}} & 0.53 & \multirow{2}{*}{\multicolumn{2}{|c|}{$\begin{array}{c}+102 \\
t(31)=9.73 \\
p<.001 \\
+20 \\
t(31)=3.23 \\
p<.01\end{array}$}} & 3.12 & \multirow{2}{*}{\multicolumn{2}{|c|}{$\begin{array}{c}+31 \\
t(31)=4.82, \\
p<.001 \\
+16 \\
t(31)=2.39 \\
p<.05\end{array}$}} & 0.90 \\
\hline Semantic Stroop effect & & & 0.19 & & & 0.24 & & & 0.73 & & & 0.06 \\
\hline
\end{tabular}


sidered alongside the nonsignificant main effect of color location $[F(1,65)=0.15, p=.70$, n.s.], these results suggest that the location of the stimulus (OVP vs. random) had no significant influence on the corresponding colornaming latencies.

Similarly, the analysis of differences in percentages of errors (see Table 3 ) revealed significant main effects of both the type of Stroop effect $[F(1,65)=21.26, p<.001$, $\left.\eta_{\mathrm{p}}^{2}=.25\right]$ and of letter coloring/cuing $[F(1,65)=11.74$, $\left.p<.001, \eta_{\mathrm{p}}^{2}=.15\right]$. These two factors also interacted significantly $\left[F(1,65)=11.37, p<.001, \eta_{\mathrm{p}}^{2}=.15\right]$, thus revealing that coloring and cuing a single letter (vs. all letters) in a word significantly reduced percentages of errors for the standard Stroop effect $[t(66)=3.89, p<.001$, $\left.\eta_{\mathrm{p}}^{2}=.19\right]$ but had no effect on percentages of errors in the case of the semantically based Stroop effect $[t(66)=0.79$, $p=.43$, n.s.].

Once again, the latter interaction was not influenced by the location of the stimulus, as the nonsignificant threeway interaction indicates $[F(1,65)=1.18, p=.28$, n.s. $]$. Taken alongside the nonsignificant main effect of color location $[F(1,65)=0.03, p=.86$, n.s.], these results suggest that the location of the stimulus (OVP vs. random) had no influence on differences in percentages of errors.

\section{Discussion}

The evidence reported in the current literature on the effects of coloring and cuing a single letter (as opposed to all letters) in a word seems contradictory: Manwell et al. (2004) reported that this type of procedural intervention reduces the standard Stroop effect and eliminates the semantically based Stroop effect, whereas Augustinova and Ferrand (2007) reported the reduction of the standard Stroop effect but consistently failed to replicate the elimination or even the reduction of the semantically based Stroop effect (see Table 1). Since the latter effect has important implications for the debate concerning SA automaticity, the purpose of the present article was to provide clearer evidence concerning whether the semantically based Stroop effect can be reliably eliminated or whether it remained undetected due to insufficient statistical power in the study conducted by Manwell and colleagues. To this end, two experiments were conducted. Experiment 1 was an exact replication of Manwell et al. with French words. Experiment 2 was identical to Experiment 1, except that it controlled for initial fixation and also tested the OVP (as in Parris et al., 2007).

The results of both experiments are clear-cut. In line with previous studies (Augustinova \& Ferrand, 2007; Besner \& Stolz, 1999; Brown, Joneleit, Robinson, \& Brown, 2002; Manwell et al., 2004; Parris et al., 2007), coloring and cuing a single letter (vs. all letters) in a word significantly reduced the standard Stroop effect. However, contrary to Manwell et al.'s results but in line with those obtained by Augustinova and Ferrand, these manipulations consistently failed to eliminate or even reduce the semantically based Stroop effect. Indeed, significant semantically based Stroop effects were observed in both experiments, independently of whether the cued/colored letter was located randomly (in the initial, middle, or end position) or always appeared in the OVP4 and independently of whether or not the cued/colored letter was located at the initial fixation point. This level of consistency, revealing effects of such a scale obtained in such a large sample, suggests that these results should be considered to be reasonably reliable. This conclusion is reinforced by the results of an associated $z$ test (Winer, 1971) combining Experiments 1 and 2. Indeed, Winer's $z=6.6(p<.01)$ confirmed that the significant semantically based Stroop effect in the single-letter colored/cued condition replicates across experiments.

This failure to observe the elimination of the semantically based Stroop effect complements the results obtained by Augustinova and Ferrand (2007). Taken together, these different findings combine to support the idea that SA in the Stroop task seems to be difficult to eliminate and can, therefore, be considered to be automatic, in the sense that it occurs without intent and cannot be prevented. This conclusion is also supported by findings obtained with the semantic priming paradigm, which shows that naming the color of a single letter within a prime word does not eliminate semantic priming (MacNevin \& Besner, 2002) and that searching for a letter in a word neither eliminates the SA of the corresponding word (Hutchison \& Bosco, 2007) nor eliminates semantic priming (see, e.g., Tse \& Neely, 2007), at least when the target words have a low frequency of occurrence in print.

Furthermore, Heil, Rolke, and Pecchinenda (2004) have argued that the absence of SA could not be validly inferred from the lack of a semantic priming effect on response time, since this type of null effect can occur while a negative-going ERP around $400 \mathrm{msec}$ (used as an indicator of SA) is detected. Thus, an apparent elimination of the semantically based Stroop effect does not necessarily mean that SA is blocked or nonexistent (Neely \& Kahan, 2001). Indeed, an ERP study analogous to the present behavioral experiments (Flaudias, Ferrand, \& Augustinova, 2009) consistently showed that the semantically based Stroop interference elicited a negative-going ERP around $400 \mathrm{msec}$.

To summarize, the present article indicates that coloring and cuing a single letter (as opposed to all letters) in a word reduce the amplitude of the standard Stroop effect (see also Augustinova \& Ferrand, 2007; Besner \& Stolz, 1999; Manwell et al., 2004) but not the amplitude of the semantically based Stroop effect. Although these findings are consistent with Augustinova and Ferrand, future research should concentrate on identifying whether the presence of a semantically based Stroop effect of the same amplitude in both the single- and all-letter colored/cued condition is a reliable effect, since such results may have important implications for the ongoing debate about the conceptual definition of automaticity (see, e.g., Bargh, 1994; Neely \& Kahan, 2001; Posner \& Snyder, 1975; Reynolds \& Besner, 2006). Despite the obvious problem of interpreting null findings, the fact that the semantically based Stroop effect is insensitive to manipulations designed to narrow attention seems to be consistent with the idea "that the amount of SA that a written word pro- 
duces is not affected by concurrently operating attentiondemanding mental operations" (Neely \& Kahan, 2001, p. 73) and can be thus considered to be capacity free.

It should be noted that this renewed demonstration of the fact that coloring and cuing a single letter (vs. all letters) in a word significantly reduce the standard but not the semantically based Stroop effect also raises the possibility that narrowing attention specifically reduces interference due to a nonsemantic, task-relevant competition between responses. In particular, it is conceivable that it reduces the activation of articulatory codes (Neely \& Kahan, 2001) or helps to separate the products resulting from the processing of the color and word dimensions (Manwell et al., 2004). Another possibility is that narrowing attention through single-letter coloring/cuing permits a better adaptation to the task-specific response criteria, since it enables participants to exert additional control over what is done with the various items of information that are automatically computed (see, e.g., Catena, Fuentes, \& Tudela, 2002 , for demonstrations of this possibility). These different possibilities (which point in very different directions) indicate that future studies will require a clear conceptual and operational definition of nonsemantic, task-relevant response competition. Given that relatively few studies have differentiated between standard and semantically based Stroop interference, it is clear that we are far from possessing a full understanding of the processes involved in this type of nonsemantic, task-relevant response competition. To summarize, these potential avenues of research provide new impetus for the research project suggested by Neely and Kahan.

\section{AUTHOR NOTE}

The first and the third authors contributed equally to the present work. All the authors thank Derek Besner, Jonathan Grainger, Benjamin Parris, and James Neely for their helpful advice, comments, and suggestions on previous drafts of the manuscript. Correspondence concerning this article should be addressed to M. Augustinova or L. Ferrand, CNRS and University Blaise Pascal, Laboratoire de Psychologie Sociale et Cognitive, 34, avenue Carnot, 63037 Clermont-Ferrand, France (e-mail: maria.augustinova@univ-bpclermont.fr; ludovic.ferrand@univ -bpclermont.fr).

\section{REFERENCES}

Augustinova, M., \& Ferrand, L. (2007). Influence de la présentation bicolore des mots sur l'effet Stroop [First-letter coloring and the Stroop effect]. L'Année Psychologique, 107, 163-179. doi:10.4074/ S0003503307002011

BARGH, J. A. (1994). The four horsemen of automaticity: Awareness, intention, efficiency, and control in social cognition. In R. S. Wyer, Jr., \& T. K. Srull (Eds.), Handbook of social cognition (2nd ed., Vol. 1, pp. 1-40). Hillsdale, NJ: Erlbaum.

BESNER, D., \& STOLZ, J. A. (1999). What kind of attention modulates the Stroop effect? Psychonomic Bulletin \& Review, 6, 99-104.

Besner, D., Stolz, J. A., \& Boutilier, C. (1997). The Stroop effect and the myth of automaticity. Psychonomic Bulletin \& Review, 4, 221-225.

Brown, T. L., Gore, C. L., \& CARR, T. H. (2002). Visual attention and word recognition in Stroop color naming: Is word recognition "automatic"? Journal of Experimental Psychology: General, 131, 220-240.

Brown, T. L., Joneleit, K., Robinson, C. S., \& Brown, C. R. (2002). Automaticity in reading and the Stroop task: Testing the limits of involuntary word processing. American Journal of Psychology, 115, 515-543.
Catena, A., Fuentes, L. J., \& Tudela, P. (2002). Priming and interference effects can be dissociated in the Stroop task: New evidence in favor of the automaticity of word recognition. Psychonomic Bulletin \& Review, 9, 113-118.

Dalrymple-AlFord, E. C. (1972). Associative facilitation and interference in the Stroop color-word task. Perception \& Psychophysics, 11, 274-276.

Flaudias, V., Ferrand, L., \& Augustinova, M. (2009, November). Accès automatique au sens du mot: Analyse de sa remise en question dans une tâche Stroop à l'aide de mesures de potentiels évoqués [Automatic semantic activation in the Stroop task with ERPs]. Paper presented at the annual meeting of the ARC (Association pour la Recherche Cognitive), Rouen, France.

Forster, K. I., \& Forster, J. C. (2003). DMDX: A Windows display program with millisecond accuracy. Behavior Research Methods, Instruments, \& Computers, 35, 116-124.

Heil, M., Rolke, B., \& Pecchinenda, A. (2004). Automatic semantic activation is no myth: Semantic context effects on the N400 in the letter-search task in the absence of response time effects. Psychological Science, 15, 852-857.

Hutchison, K. A., \& Bosco, F. A. (2007). Congruency effects in the letter search task: Semantic activation in the absence of priming. Memory \& Cognition, 35, 514-525.

KLEIN, G. S. (1964). Semantic power measured through the interference of words with color-naming. American Journal of Psychology, 77, 576-588.

MACLEOD, C. M. (1991). Half a century of research on the Stroop effect: An integrative review. Psychological Bulletin, 109, 163-203.

MacLeod, C. M. (2005). The Stroop task in cognitive research. In A. Wenzel \& D. C. Rubin (Eds.), Cognitive methods and their application to clinical research (pp. 17-40). Washington, DC: American Psychological Association.

MacNevin, C., \& Besner, D. (2002). When are morphemic and semantic priming observed in visual word recognition? Canadian Journal of Experimental Psychology, 56, 112-119.

Manwell, L. A., RoberTs, M. A., \& Besner, D. (2004). Single letter coloring and spatial cuing eliminates a semantic contribution to the Stroop effect. Psychonomic Bulletin \& Review, 11, 458-462.

NeELY, J. H., \& KAHAN, T. A. (2001). Is semantic activation automatic? A critical re-evaluation. In H. L. Roediger III, J. S. Nairne, I. Neath, \& A. M. Surprenant (Eds.), The nature of remembering: Essays in honor of Robert G. Crowder (pp. 69-93). Washington, DC: American Psychological Association.

New, B., Pallier, C., Brysbaert, M., \& Ferrand, L. (2004). Lexique 2: A new French lexical database. Behavior Research Methods, Instruments, \& Computers, 36, 516-524.

O’Regan, J. K., \& JACOBS, A. M. (1992). Optimal viewing position effect in word recognition: A challenge to current theory. Journal of Experimental Psychology: Human Perception \& Performance, 18, 185-197.

Parris, B. A., Sharma, D., \& Weekes, B. (2007). An optimal viewing position effect in the Stroop task when only one letter is the color carrier. Experimental Psychology, 54, 273-280.

Posner, M. I., \& SNYDER, C. R. R. (1975). Attention and cognitive control. In R. L. Solso (Ed.), Information processing and cognition: The Loyola symposium (pp. 55-83). Hillsdale, NJ: Erlbaum.

REYNOLDS, M., \& BESNER, D. (2006). Reading aloud is not automatic: Processing capacity is required to generate a phonological code from print. Journal of Experimental Psychology: Human Perception \& Performance, 32, 1303-1323.

Stolz, J. A., \& Besner, D. (1999). On the myth of automatic semantic activation in reading. Current Directions in Psychological Science, 8, 61-65.

Stroop, J. R. (1935). Studies of interference in serial verbal reactions. Journal of Experimental Psychology, 18, 643-662.

Tse, C.-S., \& NeEly, J. H. (2007). Semantic priming from letter-searched primes occurs for low- but not high-frequency targets: Automatic semantic access may not be a myth. Journal of Experimental Psychology: Learning, Memory, \& Cognition, 33, 1143-1161.

WINER, B. J. (1971). Statistical principles in experimental design (2nd ed.). New York: McGraw-Hill. 


\section{NOTES}

1. Analyses suggested and conducted by one of the reviewers (J. Neely). Note that the latter analyses are in contradiction to the power analyses reported by Manwell et al. (2004).

2. In both experiments reported in Manwell et al. (2004), the cued/ colored letter appeared at the beginning, middle, or end of the target word. Since the initial fixation cross appeared in the center of the screen and all the stimuli were presented with the middle letter positioned at the fixation point, cued/colored letters located at the beginning and the end positions were consequently displayed at a location other than the fixation point.

3. It should be noted that in this procedure, Parris et al. (2007) reported that single-letter coloring reduced the magnitude of the standard Stroop effect at every letter position except at the optimal viewing position (OVP), which corresponds to the readers' usual initial fixation and is located just to the left of the center of the word (see, e.g., O'Regan \& Jacobs, 1992). We therefore also included the OVP in the design of Experiment 2.

4. Parris et al. (2007) reported that a single-letter coloring procedure reduced the standard Stroop effect except when the colored letter was located at the OVP. In Experiment 2, there was no evidence for this type of influence of OVP on either the standard or semantically based Stroop effects. This finding, however, is consistent with O'Regan and Jacobs (1992), who found that OVP conferred no advantage for short words (five-letter words) in a naming task. As was suggested by one reviewer (B. Parris), the lack of an OVP effect could also be due to the lack of variation in the letter positions, which allows participants to gain practice in overriding the cost associated with processing at that position. It is also plausible that the arrow-cuing procedure might eliminate the costs involved in processing the stimuli from the OVP onward (since this represents an additional spatial cue, it could prevent the optimum distribution of spatial attention). Finally, the use of response set colors to color the nontarget letters could have prevented the spread of spatial attention from the OVP and might, as a result, have prevented the cost in performance observed by Parris et al. at that position.

(Manuscript received November 12, 2009; revision accepted for publication July 31,2010 .) 